\title{
Designing and Execution of 3-Level Stabilizing unit in Hybrid Photovoltaic and Wind Energy Systems
}

\author{
Piyush Kumar \\ M.Tech Scholar \\ EX Department \\ Rabindra Nath Tagore University \\ Raisen, Madhya Pradesh, India \\ piyushkumar9300@gmail.com
}

\author{
Nand Lal Shah \\ Assistant Professor \\ EX Department \\ Rabindra Nath Tagore University \\ Raisen, Madhya Pradesh, India \\ nandlalshah0177@gmail.com
}

\begin{abstract}
The fundamental concept of control for a threelegged IGBT-based voltage source regulator-based stabiliser was thoroughly discussed in this paper. The proposed technique's effectiveness and efficiency in a twomachine based model is demonstrated by a comparative analysis in a grid integrated hybrid system. The hybrid solar wind system produces 400 volts of voltage. A comparative analysis of the various stabilisation control algorithms is currently underway. Three algorithms have been used to implement the system. Particle swarm optimization (PSO) control, hysteresis control, and neural network modified PSO control are all possible with PI..
\end{abstract}

Keywords: Solar photovoltaic system, active power, reactive power, power stability system, grid connected system.

\section{INTRODUCTION}

Technique by which electricity is produced with the means of renewable energy captures and transform a enviourmentally formed energy flux, including energy from wind, sun, heat, or tides, into electrical energy. Time-period constants, cycles, and energy densities fluctuate in natural world.In contrast to classical fossil-fuel as well as nuclear electricity producing facilities, these can be positioned at some spacing from their fuel sources, electricity generation though energies like wind or sun mechanisms must be positioned where even the enviourmental energy flux takes place to plug these sources of energy. Such technologies which rely on renewable energies also implement a conceptual framework that differs from standard energy sources in that renewable energy can be assumed of as factory - made energy, with the producing mechanism accounting for the majority of expenses, exterior energy, and material inputs.

Ensure that appropriate initiation capacity arises to achieve the requirement of electricity at all times of the 365 days in the year is an essential consideration of systematic power system. The capability of power system to acquire the requirement may be unsatisfactory due to failure of machinery, systematic maintenance, or an absence of on requirement of producing assets (specifically for changeable nature based resources). Grid is organised in project as upcoming peak requirements of trends and forecast each producers relative effort to attain a trustable energy supply. Variable renewable energy (VRE), such as wind based energy or solar PV, services are customized complexity to the system whenever it generates throughout peak desired periods. VRE can enable withhold external financing in classical electricity generating and sending power grid by offering capacity value.

\section{LITERATURE REVIEW}

\section{Reactive Power Managing within Power Grids based on} Renewable Energies

Renewable energy generators (REGs) with power electronic converter (PEC) interfaces are increasingly being applied into the power grid. One of the key power system variables, reactive power, is associated with elevated renewable power loading, causing steady-state voltage and dynamic or transient stability problems. To help make sure a consistent and predictable power grid, it is essential for keeping and organize sufficient reactive power reserves. a thorough review of relevant literature on reactive power management in renewable-rich power grids The reactive energy demands for REGs stipulated in various grid codes are summarized in order to assess their suitability for future communication necessities. The reactive power compensation capability and control schemes of the PEC-interfaced REGs are covered in depth. Regular reactive power support equipments and PECinterfaced reactive power support equipments conducted as a critical role in the reactive power planning of better efficient in power grids relying on renewable energy sources, and their operability and barriers are thoroughly examined in [4.] 
Through the usage of two control knobs - active power suppression and reactive power support - the research has revealed the usage of non-smart PV inverters to mitigate overvoltage and undervoltage concerns. This control is regionally feasible from the standpoint of the consumer, while also benefiting the utility by increasing feeder voltage. On practically implemented functioning microgrid testbed, the proposed controlling strategies were efficaciously implemented in actual timeframe. However, the reactive power was limited due to the inverters' power aspects limitations (95\%), which could have been enhanced if latest designed inverters having a wider power aspects context becoming available.Using the emerging selfsufficient microgrid resources of the UCR testbed in [5,] efficient voltage regulation algorithm deployment is available in the future after obtaining appropriate incentives from the functionality as compensate for lost creation due to diminishment.

\section{METHODOLOGY}

To model components of Hybrid-Renewable-EnergySystems, researchers have established a variety of modelling techniques. Individual elements effectiveness is modelled using either deterministic or probabilistic methods. This section covers the fundamental modelling structures of solar and wind energy systems, as well as the modelling of PSS control system.

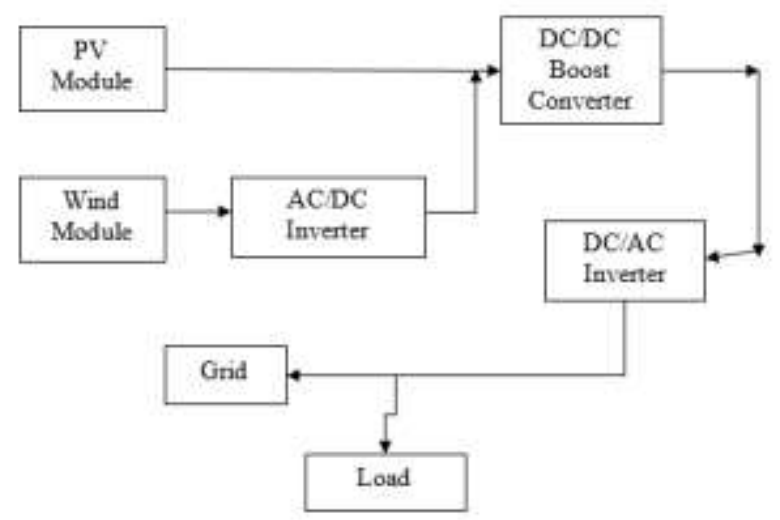

Figure 1Basic Model of HRES

Grid linked Photovoltaic systems with a standby Energy Storage system are usually attatched to the utility grid. The organisation or layput of the system involves various benefits, having auctioning excess PV electricity to the grid, charging the battery system throughout least hours, and buying energy from the utility to feast the loads whenever PV and battery power are unsatisfactory. Renewable PV sources can't guarantee a ongoing energy supply, which can lead to desired production disparity, specifically throughout least timeframes when PV generates further energy and throughout uttermost timeframe whenever load requirement spikes.PV cells have a single operating point where the cell's current (I) and voltage (V) produce the maximum amount of power. These numbers represent a specific resistance.

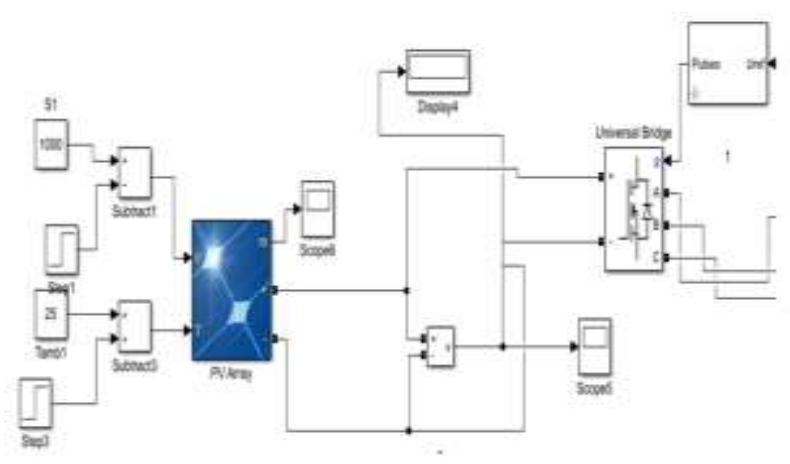

Figure 2 PV Module

Table 1 : Photo - Voltaiccomponent variables

\begin{tabular}{|l|l|}
\hline Prototype & 1 Soltech $1 \mathrm{STH}$ \\
\hline Uttermost Power & 212.4 joule/sec \\
\hline Quantity of aligned strings & 40.0 \\
\hline $\begin{array}{l}\text { Quantity of sequenced } \\
\text { prototype }\end{array}$ & 10.0 \\
\hline Open circuitry voltage & 35.2 Volts \\
\hline Shot-circuitry current & 6.73 Ampere \\
\hline Irradiation & 500 to $1000 \mathrm{wb} / \mathrm{m}^{2}$ \\
\hline Temperature & $26^{0} \mathrm{C}$ \\
\hline
\end{tabular}

The horizontal axis type model (HAWT) and the vertical axis type model (VAWT) are the two major categories of wind turbines. In most wind industry sectors, HAWTs are the top choice over VAWTs resulting in a higher efficiency. Despite having the lowest efficiency than HAWTs, VAWTs have the benefit of capturing wind energy from any way. It also has a lower cut-off speed, allowing it to produce power even when the wind speed is low.

There has been quite a massive increase in interest in employing offshore wind resources in recent years. As an outcome, floating horizontal axis wind turbines (FHAWTs) and vertical axis wind turbines (FVAWTs) are becoming more commercially viable. A generator, impelling hub and blades, gear-case, and spire are just a few of the aspects and subassemblies that make up a wind turbine.

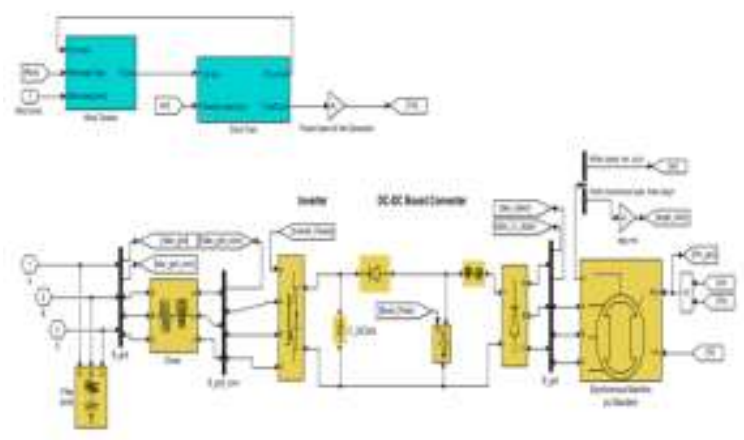

Figure 3 Modelled Wind System 
Table 2 :Wind Based Energy System variables

\begin{tabular}{|l|l|}
\hline Rate of Wind & $10.00 \mathrm{~m} / \mathrm{sec}$ \\
\hline Quantity of wind generators & 80.0 \\
\hline Minimal power & $2 \mathrm{MW}$ \\
\hline Frequency & $50 \mathrm{hertz}$ \\
\hline Line to line voltage & $411 \mathrm{~V}$ \\
\hline Friction factor & 0.01 \\
\hline Quantity of poles & 1 \\
\hline Inertia constant & 0.61 \\
\hline
\end{tabular}

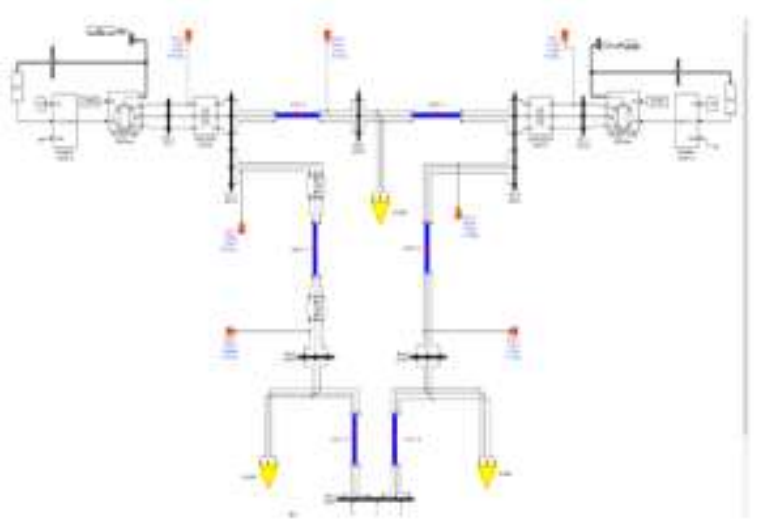

Figure 4 Power System Modelling

Table 3 : Power System Parameters

\begin{tabular}{|l|l|}
\hline Minimal power & $128 \mathrm{MW}$ \\
\hline $\begin{array}{l}\text { Rate of recurrence } \\
\text { (frequency) }\end{array}$ & 50 hertz \\
\hline Line to line voltage & $13.8 \mathrm{KV}$ \\
\hline Friction factor & 0 \\
\hline Number of poles & 1 \\
\hline Inertia constant & 2.35 \\
\hline Stator Resistance & $1 \times 10^{-7}$ ohms \\
\hline Rotor type & Round \\
\hline Load flow & PV \\
\hline
\end{tabular}

As a power system stabilizer, supplement excitation control of low frequency oscillations is well known (PSS). It was created to help dampen electromechanical oscillations by modifying the generator excitation. Despite the fact that several researchers have used advanced control methods for reducing the recommended optimal solution, power system utilities continue to prefer the traditional lead-lag power system stabilizer structure. The reason for this could be the ease with which internet based tuning can be done and the lack of confidence in the stabilization of certain adaptive or changeable framework methods.

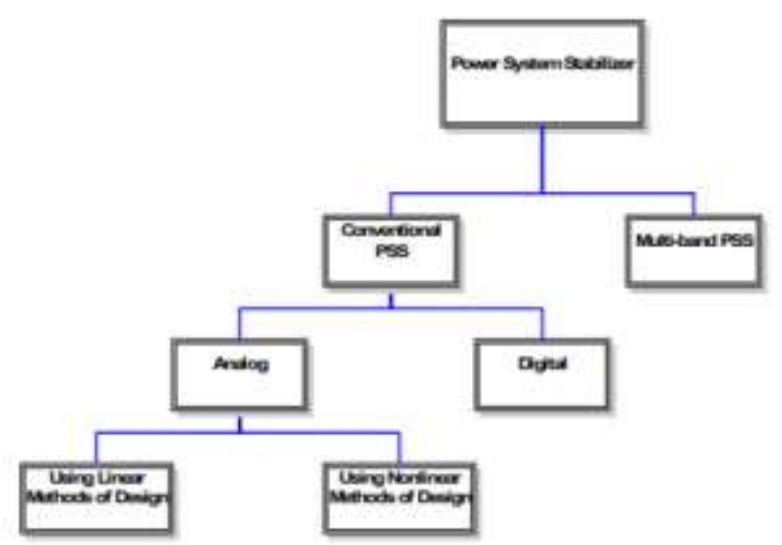

Figure 5 Power System Stabilizer

A Power System Stabilizer's primary role is to enlarge the stabilization limits of the system by modifying alternator excitation and damping the oscillation of the alternator's rotor comparative to one another. The oscillations that because concern are usually between 0.2 and $3.0 \mathrm{~Hz}$ in frequency. The PSS transform the over-frequency component to the appropriate constant frequency before determining the reference voltage.

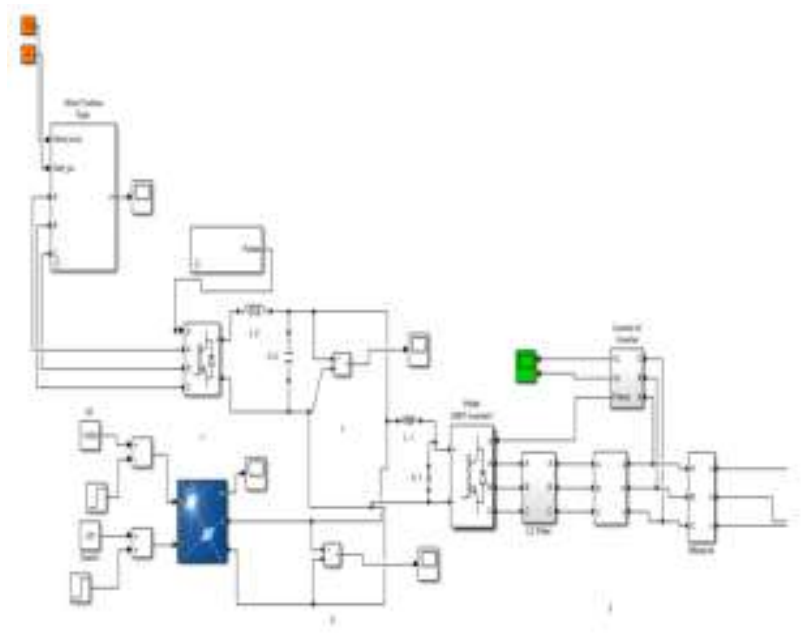

Figure 6 Modelled Hybrid System (Photovoltaic +wind Energy) in MATLAB

In terms of protecting loads, a voltage stabilizer is intended to ensure a steady voltage level to include a continuous supply in the face of any variability or modifications in supply. Voltage regulators are typically employed to keep a steady voltage, and these voltage regulators offer a constant voltage to the load. The research helps to stabilize the hybrid wind energy system's output voltage. 


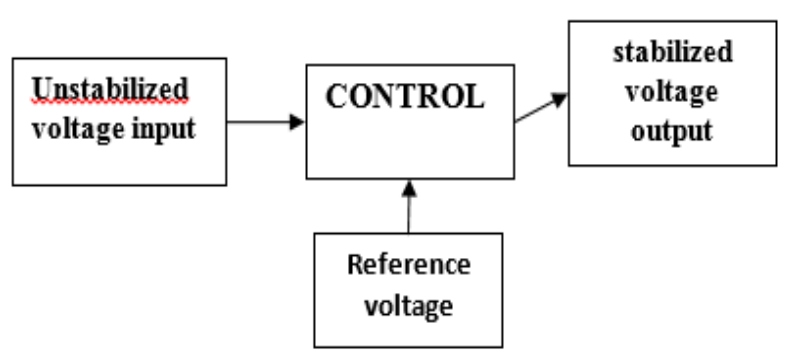

Figure 7 Block Diagram of PSS

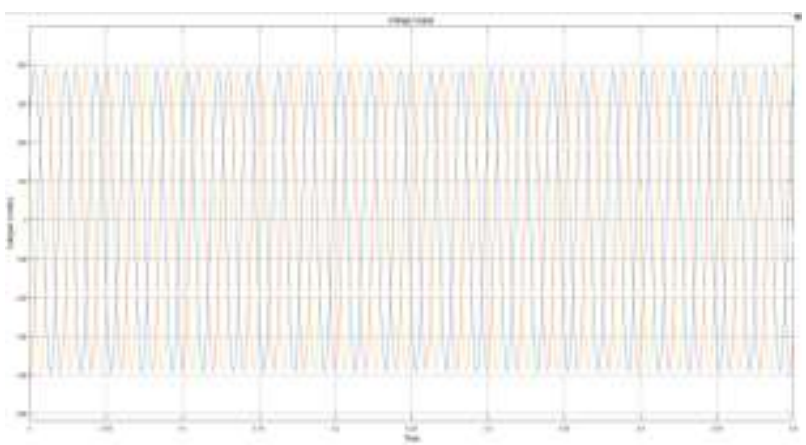

Figure 8 Voltage output from the system excluding stabilizer

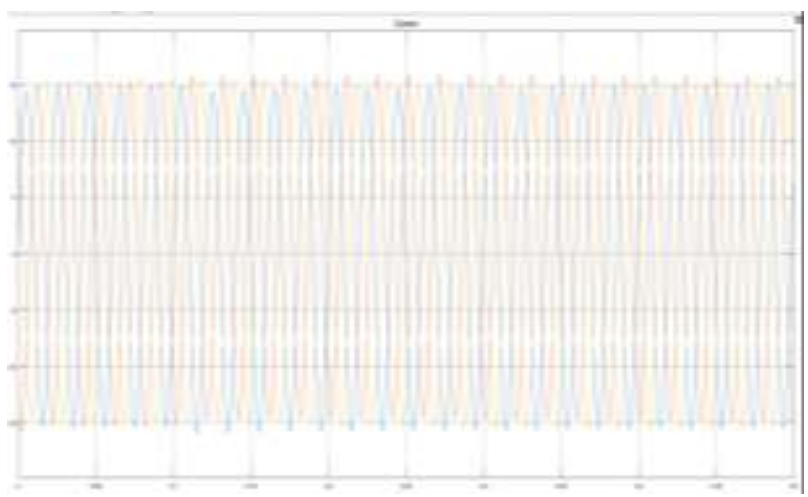

Figure 9 Current output from the system excluding stabilizer

The various control methods used with the stabilizer in order to evaluate its effectiveness with respect to rotor angle stabilization and THD level assessment. PI-hysteresis control, particle Swarm Optimization (PSO), and PSO with neural network control are among the methods mentioned.

\section{RESULT AND DISCUSSION}

A hybrid PSO-neural network power system stabiliser (PSS) for damping electro - mechanical mechanisms of oscillation and improving power system synchronous stabilization. A front-end traditional analogue PSS layout, a PSOrelying optimizer, and an artificial neural network (ANN) relying stabiliser make up the hybrid PSS. The work compared the three PSS control techniques: a) PI with PSS hysteresis, b) PSO based control of PSS, and c) PSO with neural network control of PSS.

Scenario 1: A grid-connected hybrid PV/wind system with no stabilizer.
Prior to its incorporation with two system-dependent power systems, the level of distortion in the system's voltage output is investigated using wide variety of stabilizer regulation. In a comparative evaluation of power system stability, the machineries' rotor angle stability is also evaluated by comparing.

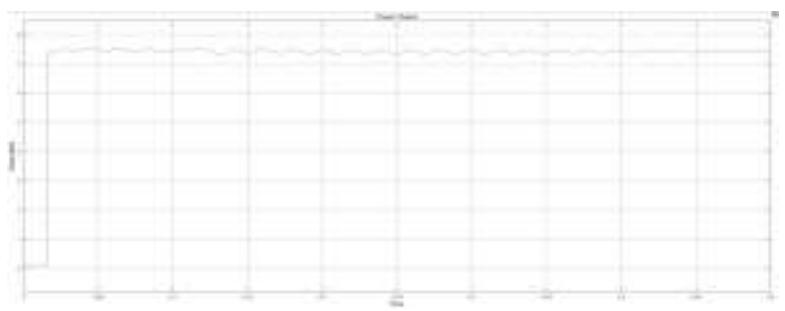

Figure 10 Excluding stabilizer, the system's active power outcome is shown

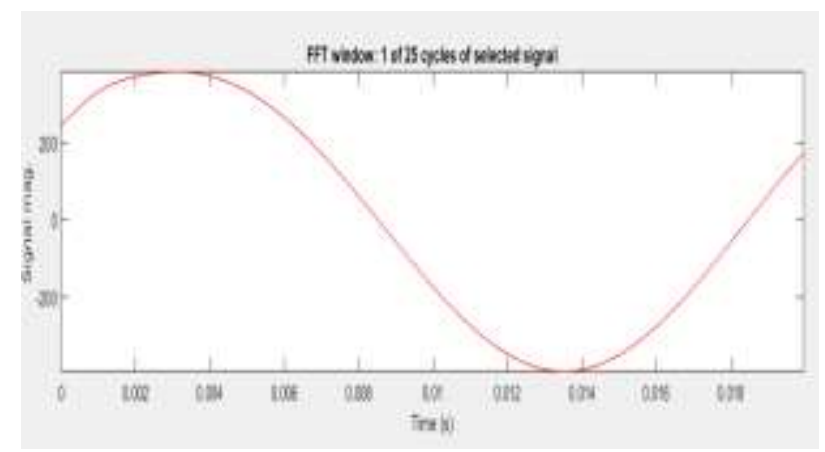

Figure 11 Fourier transform assessment of the system's voltage output excluding a stabilizer

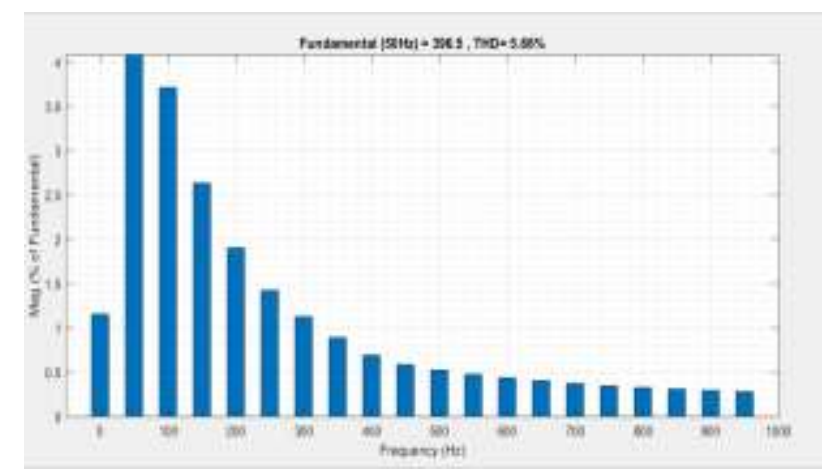

Figure 12 THD (Total Harmonic Distortion) in Voltage Output from System excluding Stabilizer

Scenario 2: Grid-connected hybrid PV/wind system with PI and hysteresis stabilizer control 


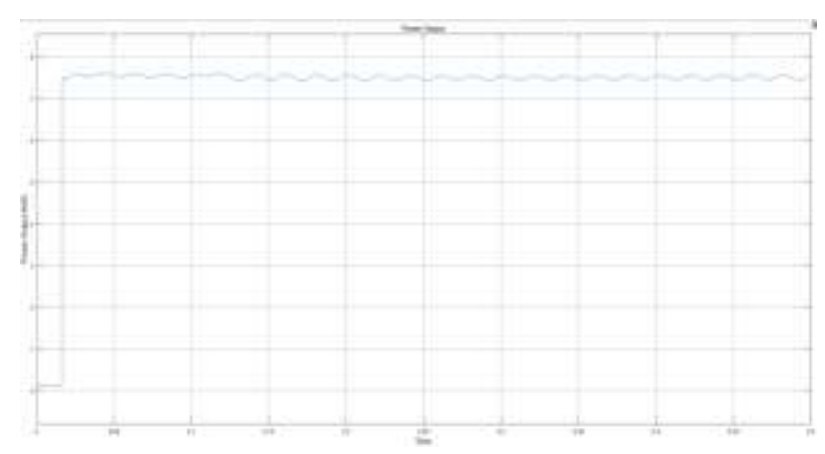

Figure 13 Active power throughput from the system with PI and stabilizer hysteresis control

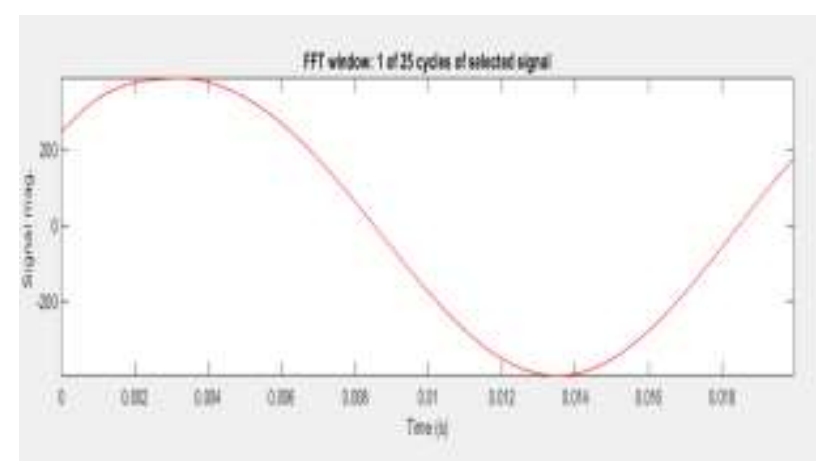

Figure 14 Fourier transform assessment of the system's voltage outcome with PI and stabilizer hysteresis control

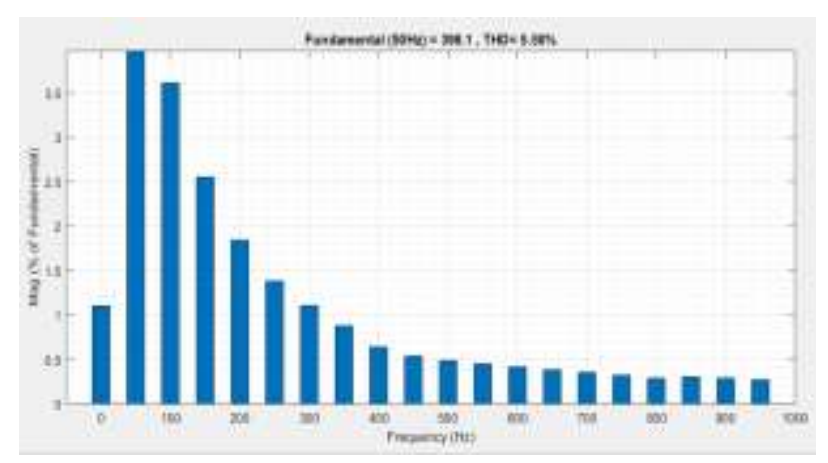

Figure 15 Harmonic distortion percent in the system's voltage outcome with PI and stabilizer hysteresis control

In this paper, a hybrid system was created in the MATLAB/SIMULINK environment and then integrated with a two-generator power system. The work looked at the level of THD in the voltage output from the hybrid system and suggested various controls for the power system stabilizer. The angle stability of the power system is also investigated using the stabilizer. The hybrid system's output voltage is 400 volts.
Table 4: ComparingTotal Harmonic Distortion in output voltage after using different algorithms

\begin{tabular}{|l|l|}
\hline $\begin{array}{l}\text { Level of Total Harmonic } \\
\text { Distortion in voltage output } \\
\text { after various control } \\
\text { algorithms }\end{array}$ & $\begin{array}{l}\text { Total Harmonic Distortion } \\
(\%) \text { level in voltage output } \\
\text { waveforms }\end{array}$ \\
\hline $\begin{array}{l}\text { Total Harmonic Distortion \% } \\
\text { in base system excluding } \\
\text { stabilizer }\end{array}$ & $5.66 \%$ \\
\hline $\begin{array}{l}\text { Total Harmonic Distortion \% } \\
\text { in system including PI and } \\
\text { Hysteresis controlled } \\
\text { stabilizer }\end{array}$ & $5.50 \%$ \\
\hline $\begin{array}{l}\text { Total Harmonic Distortion \% } \\
\text { in system including PSO } \\
\text { controlled stabilizer }\end{array}$ & $4.24 \%$ \\
\hline $\begin{array}{l}\text { TOTAL HARMONIC } \\
\text { DISTORTION \% in system } \\
\text { including PSO and neural } \\
\text { network controlled stabilizer }\end{array}$ & $3.36 \%$ \\
\hline
\end{tabular}

\section{CONCLUSION}

Optimization relying linearly controlled design is used to tune the variables of the power system stabiliser. This research focuses on the designing and execution of a threelevel stabiliser in a hybrid PV Wind Energy system that is integrated with the power system. The fundamental concept of control for a three-legged IGBT-based voltage source regulator-based stabiliser was explained clearly. The proposed technique's effectiveness and efficiency in a twomachine based model is demonstrated by a comparative analysis in a grid integrated hybrid system. The hybrid solar wind system produces 400 volts of voltage. The results were discussed in the table 4 in earlier section.

\section{REFERENCE}

[1] Wang, Q., Cheng, M., Jiang, Y., Zuo, W., \& Buja, G. (2018). A Simple Active and Reactive Power Control for Applications of Single-Phase Electric Springs. IEEE Transactions on Industrial Electronics, 65(8), 6291-6300. https://doi.org/10.1109/TIE.2018.2793201

[2] Hamouda, N., Babes, B., Kahla, S., Soufi, Y., Petzoldt, J., \& Ellinger, T. (2019). Predictive Control of a Grid Connected PV System Incorporating Active power Filter functionalities. Proceedings - 2019 1st International Conference on Sustainable Renewable Energy Systems and Applications, ICSRESA 2019, 0-5. https://doi.org/10.1109/ICSRESA49121.2019.9182655

[3] Dehghani Tafti, H., Maswood, A. I., Lim, Z., Ooi, G. H. P., \& Raj, P. H. (2016). A review of active/reactive power control strategies for PV power plants under unbalanced grid faults. Proceedings of the 2015 IEEE Innovative Smart Grid Technologies - Asia, ISGT ASIA 
2015, Mv, 1-6. https://doi.org/10.1109/ISGTAsia.2015.7387144

[4] Mishra, M. K., \& Lal, V. N. (2020). An improved methodology for reactive power management in grid integrated solar PV system with maximum power point condition. Solar Energy, 199(September 2019), 230-245. https://doi.org/10.1016/j.solener.2020.02.001

[5] Miao, X., \& Ilic, M. D. (2021). High Quality of Service in Future Electrical Energy Systems: A New TimeDomain Approach. IEEE Transactions on Sustainable Energy, $\quad 12(2)$, https://doi.org/10.1109/TSTE.2020.3038884

[6] Nian, H., \& Song, Y. (2014). Direct power control of doubly fed induction generator under distorted grid voltage. IEEE Transactions on Power Electronics, 29(2), 894-905. https://doi.org/10.1109/TPEL.2013.2258943

[7] Adnani, K., Vaez-Zadeh, S., \& Jabbarnejad, A. (2020). Flexible Active/Reactive Power Ripple Control of Grid-Connected Voltage Source Converters under Unbalance Conditions. IEEE International Symposium on Industrial Electronics, 2020-June, 1022-1027. https://doi.org/10.1109/ISIE45063.2020.9152529

[8] Gao, S., Zhao, H., Gui, Y., Zhou, D., \& Blaabjerg, F. (2021). An improved direct power control for doubly fed induction generator. IEEE Transactions on Power Electronics, 36(4), 4672-4685. https://doi.org/10.1109/TPEL.2020.3024620

[9] Talha, M., Raihan, S. R. S., \& Rahim, N. A. (2020). PV inverter with decoupled active and reactive power control to mitigate grid faults. Renewable Energy, 162, 877-892. https://doi.org/10.1016/j.renene.2020.08.067

[10] Amenedo, J. L. R., Gomez, S. A., Alonso-Martinez, J., \& De Armas, M. G. (2021). Grid-Forming Converters Control Based on the Reactive Power Synchronization Method for Renewable Power Plants. IEEE Access, 9, 67989-68007.

https://doi.org/10.1109/ACCESS.2021.3078078

[11] Mishra, M., \& Lal, V. N. (2021). An Advanced Proportional Multiresonant Controller for Enhanced Harmonic Compensation with Power Ripple Mitigation of Grid-Integrated PV Systems under Distorted Grid Voltage Conditions. IEEE Transactions on Industry Applications, 57(5), 5318-5331. https://doi.org/10.1109/TIA.2021.3091046

[12] Islam, M. M., Hossain, E., Padmanaban, S., \& Brice, C. W. (2020). a New Perspective of Wind Power Grid Codes under Unbalanced and Distorted Grid Conditions. IEEE Access, 8, 15931-15944. https://doi.org/10.1109/aCCESS.2020.2966907
[13] Brahmi, H., \& Dhifaoui, R. (2021). A Study of a DC/AC Conversion Structure for Photovoltaic System Connected to the Grid with Active and Reactive Power Control. Complexity, 2021. https://doi.org/10.1155/2021/9967577

[14] Mishra, M. K., \& Lal, V. N. (2021). An enhanced control strategy for harmonic current suppression of gridconnected PV system without phase-locked loop under distorted grid voltage conditions. Conference Proceedings IEEE Applied Power Electronics Conference and Exposition - APEC, 2702-2707.

https://doi.org/10.1109/APEC42165.2021.9487359 